\title{
Report of the Founding Meeting of the Indian Labour History Association
}

\author{
Dilip Simeon \\ Consulting Editor, International Labor and Working-Class History
}

A decision to found an association of scholars of Indian labor history was taken at the Amsterdam workshop on South Asian labour history in October 1995. The concept was founded on the substantial amount of work done or in progress, combined with the perception that coordinated effort would highlight the significance to the social sciences of labor history and enhance our scholarly activity. The founding meeting of this body was held in the School of Social Sciences at Jawaharlal Nehru University campus in New Delhi on December 15-16, 1996. Fifteen persons participated in the discussions, which covered thematic and organizational issues. Professor Sabyasachi Bhattacharya of the Centre for Historical Studies, JNU, chaired the first day's proceedings and Dr Vijay Prashad of Trinity College, Connecticut, United States, chaired the discussions on the second day. After a brief review of the subject matter of the previous conference, the meeting considered the possibilities of cooperative work in the field and the boundaries of the proposed association's interests. The chairperson reminded the gathering that it represented the culmination of some two decades of scholarship in the field. The point was raised however, that focused work was lacking, and interest in the subject-indeed, in the discipline of history itself-was at an ebb. Professor Bhattacharya said that the loss of the socialist paradigm constituted a partial explanation for this dilemma, but insisted that historical research ought not to be subject to the constraints of prejudged schema.

The perspectives attached to the invitation had outlined the conceptual focus of the association as "labor" in a broad sense and with reference to the activity of social groups subordinated to networks of capital and its colonial allies. It was suggested that a broader conceptual approach might stimulate us to take account of the complex modes of emergence of modern industrial work and the difficulties involved in applying cut and dried theoretical models to colonial history. The crystallization of class has been an ambiguous process, and we would be wise not to treat it as a static category. Apart from the study of the industrial workforce, labor history would be enriched by attention to the lives of artisans, women, and children in households, and peasant migrants to plantations within India and overseas.

Historically, laboring activity has been an object of control and repression. In South Asia this was complicated by the insertion of the Indian economy into the strategic and commercial system of British imperialism. 
The interaction between inchoate forms of capital and traditional institutions gave rise over time to hybridized forms of exploitation and regulatory mechanisms adjusted to the needs of empire. These mechanisms drew within their ambit a range of laboring activities linking domestic labor in the villages to the work of artisans and formally employed wage earners. The social groups involved were not passive entities-they organized their lives within existent constraints and resisted the emergent work regimes in various ways. They also represented themselves in the developing political arena in collective forms such as caste blocs, trade unions, artisanal associations, and associations of nonfactory workers. Moreover, their laboring experience extended far beyond the boundaries of South Asia. Their survival strategies and cultural/political expressions-in a word, the articulation of the interests of labor-took fluid forms in South Asian history. Their story is a subject rich in detail and theoretically challenging. The idea of the Association was inspired by the need to facilitate and develop this scholarship.

The first day's proceedings took up most of the issues contained in the text of the invitation. The following are the significant elements of the debate which ensued:

1. After considerable discussion, we decided that the name of the new body should contain the term "labor history" rather than "labor studies." The latter title had been suggested as a means of adopting an interdisciplinary approach and to incorporate events and issues of a contemporary and comparative nature. However, it was felt that since we had undoubtedly come together as historians of labor, the looser definition was inappropriate. We ought to distinguish ourselves from the several groups in economic and sociological disciplines whose work came under the general rubric of "labor studies." Notwithstanding our name, we would try to transcend disciplinary sectionalism by encouraging the study (individually and as a body) of developments in areas such as the history of science and technology, environmental history, cultural studies, linguistics, and feminist theory.

2. As regards the geographic boundaries of the association's interests, it was agreed that the migration of Indian labor overseas made it artificial to place a geopolitical limit on the stated focus of work. Added to this was the fact that some scholars might find it necessary or useful to conduct comparative studies of labor in similar situations-such as other colonized territories, Eastern Europe, or the Americas.

3. Some participants argued that the category of "labor" was linked to the emergence of modern industrial class society, whose origins, therefore, ought to be our chronological and thematic boundary. Too much flexibility on this issue might lead to a loss of focus, it was argued, and it was not advisable to treat all work as labor. Others pointed to the absence of agricultural labor from the stated perspectives and wondered how this could be justified theoretically. This was well taken, although it was agreed that we were not enlarging our concerns to include peasant studies. There 
was also the matter of researching forms of labor which existed in premodern times but which disappeared under the onslaught of colonial economic relations. Most of us agreed that, given the need to question the chronological divide that has resulted in a focus on the colonial at the expense of precolonial and postcolonial periods, and to examine the "transitional" nature of colonial social relations along with the dynamics of caste and convention, it would not be wise to exclude from our purview investigations of the institutional forms and categories of premodern society. It was tentatively accepted that an ontological meaning of labor was a more viable starting point than the "wage labor" posited by capital.

Some participants made presentations about disciplinary linkages. Ravi Vasudevan suggested how an interface between labor history and cultural studies might be highlighted through a study of the production of the artifacts of culture. This led to a discussion on skill formation. Since artisanal production has traditionally been the focus of historical interest, research now needs to be diversified into such areas as the labor that produced cinematic images. Artisanal pride and aesthetics were raised as aspects of the history of labor which are under-researched. Janaki Nair presented some reflections on the significance of gender theory to labor history, and reminded the gathering that gender did not signify "women's studies." She introduced us to the work of feminist scholars whose research into work processes transcends this narrow approach to the question of gender. She stressed the theoretical lacunae in labor history and pointed out the relevance of gender to the study of urban societies. Reflections by some colleagues followed about the inadequate treatment of these matters and about the difference between a kinship economy and a laboring economy.

Marcel van der Linden spoke about the anomalous situation in Europe where a decline of labor history as a university discipline has taken place side-by-side with still-flourishing publications and a turn to the study of themes such as "nonheroic" forms of organization, coping strategies, workers as consumers, and the role of households. Labor history in the United States has been characterized by an interest in ethnicity and plural identities, law as it affects the labor movement, and some growth in work on transnational and comparative developments. There is a new trend toward collaborative scholarly projects. Dilip Simeon reported briefly on the recent teach-in on the labor movement at Columbia University, New York. Madhavan Palat shared his perceptions of the revival of the history of Russian labor by American and Russian historians seeking to transcend the stereotypes engendered during the Cold War. These developments, in his view, are producing novel and meaningful explanations of events such as the Soviet Revolution of 1917.

Discussions on the second day focused on an appraisal of aims and objects, and on defining and organizing the association's activities. It was agreed that the new body would foster scholarly interaction, sponsor re- 
search programs and collaborate with institutions whose interests mesh with ours. The group will work to maintain international links with scholars of South Asian labor history (Marcel van der Linden and Vijay Prashad agreed to coordinate overseas mailing in Europe and North America); sponsor publications, seminars, workshops, and an annual conference; promote the establishment of chapters in various Indian cities; and take steps to identify and preserve documents, biographies, memorabilia, and artifacts of labor movements. Membership is to be open rather than restrictive. Professor Sabyasachi Bhattacharya agreed to become the president for the forthcoming year. Prabhu Mohapatra and Janaki Nair accepted the onus of secretarial duties, and Rana Behal that of the treasurer. We agreed to circulate a biannual newsletter to be edited by Chitra Joshi and Dilip Simeon.

For further details please contact:

Professor Sabyasachi Bhattacharya, 163 New Campus, JNU, New Delhi, 110067 India

Prabhu Mohapatra, 180-D, Pocket C, Siddharth Extension, New Delhi, 110014 India

Janaki Nair, M.I.D.S., 79 Second Main Road, Gandhinagar, Chennai, 600020 India 